\title{
Control of Bacterial Cells Growths by Magnetic Hyperthermia
}

\author{
M. Bañobre-López ${ }^{1}$, D. Rodrigues ${ }^{2}$, B. Espiña ${ }^{1}$, J. Azeredo ${ }^{2}$, and J. Rivas ${ }^{1,3}$ \\ ${ }^{1}$ International Iberian Nanotechnology Laboratory (INL), 4715-330 Braga, Portugal \\ ${ }^{2}$ Institute for Biotechnology and Bioengineering, Centre of Biological Engineering, Universidade do Minho, Braga 4710-057, \\ Portugal \\ ${ }^{3}$ Applied Physics Department, Physics Faculty, University of Santiago de Compostela, 15782 Santiago de Compostela, Spain
}

\begin{abstract}
In this work, we report the effectiveness of magnetic hyperthermia as a potential disinfection method against food spoilage microorganisms. High structural-magnetic quality magnetite nanoparticles have been found to be effective against bacterial microorganisms in solution under an oscillating magnetic field. Samples containing both magnetite nanoparticles and Pseudomonas fluorescens cells in aqueous solution have been subjected to an alternating magnetic field of chosen amplitude $100 \mathrm{Oe}$ with frequency of $873 \mathrm{kHz}$ for different times, achieving different maximum temperatures ranging from $35^{\circ} \mathrm{C}$ to $55^{\circ} \mathrm{C}$. The subsequent colony forming units count evidenced an important decreasing of the cell survival with temperature in comparison to a conventional direct heating, ending in the total eradication of the microorganisms in relatively short times $(\sim 8 \mathrm{~min})$. This ability of magnetic hyperthermia to control bacteria cells constitutes a novel contribution to the finding of new useful applications of hyperthermia different from biomedicine.
\end{abstract}

Index Terms-Bacterial cells, magnetic hyperthermia, magnetite nanoparticles.

\section{INTRODUCTION}

$\mathbf{N}$ OWADAYS, the use of nanotechnology has established itself as a powerful tool that covers extensively a wide range of research topics and applications, going from electronics [1] to data storage [2], catalysis and energy conversion [3] and biomedicine [4], [5]. Particularly in biomedicine, the proper design of magnetic nanoparticles (MNPs) has been one of the most active research topics in order to achieve the highest specific absorption rates as possible in magnetic hyperthermia for cancer therapy applications [6]. This technique is based in the use of MNPs as heating sources when they are under an oscillating magnetic field. Basically, MNPs transform the externally provided electromagnetic energy into heat, experiencing a temperature increase that will depend on how much effective the spin relaxation processes are. In other words, it will depend on experimental measuring parameters, structural and magnetic properties of MNPs and also colloidal parameters of the solutions [7]. In the case of superparamagnetic (SPM) nanoparticles the main mechanisms of spin relaxation are related to the Neél (spin reorientation once the external magnetic field is removed) and Brown (friction of the particles with the liquid as a consequence of the torque forces in solution) relaxation processes. Iron oxide nanoparticles have been the most studied systems for biomedical applications, since they are considered biocompatible and nontoxic and can be synthetized in the single-domain superparamentic range, avoiding the magnetic coupling and particle aggregation and, therefore, being useful for in-vivo applications [8]. However, applications of magnetic hyperthermia out of the biomedical field remain unexplored. In this work, the effectiveness of magnetic hyperthermia generated by aqueous solutions containing $\mathrm{SPM} \mathrm{Fe}_{3} \mathrm{O}_{4}$ (a) PAA nanoparticles of $\sim 10 \mathrm{~nm}$ size has been evaluated as a

Manuscript received November 05, 2012; revised January 05, 2013; accepted February 05, 2013. Date of current version July 15, 2013. Corresponding author: M. Bañobre-López (e-mail: manuel.banobre@inl.int).

Color versions of one or more of the figures in this paper are available online at $\mathrm{http} / /$ ieeexplore.ieee.org.

Digital Object Identifier 10.1109/TMAG.2013.2247384 potential disinfection method against Pseudomonas fluorescens (P. fluorescens), a major food spoilage microorganism which is able to form biofilms on different surfaces, i.e. food reservoirs and water drinking systems [9]-[11]. Usually, disinfection of microorganisms related with food spoiling and water implies the use of chemicals as chlorination agents, ozone or high temperatures. Those methods alter the chemical and/or organoleptic characteristics of food and/or water. In this paper, we show not only the suitability of magnetic hyperthermia to kill bacteria cells in solution, but also its better efficiency against other conventional direct heating technique. The local temperature increase achieved in the nanoparticles by action of the alternating magnetic field is presumably much higher than the macroscopic value measured inside the whole solution. That means that even when the measured temperature does not achieve living limits, the local heating irradiated by the nanoparticles would be enough to provoke the cell death. This would allow using not so high temperatures in disinfection or sterilization processes and so preserve the physical and chemical integrity of compounds existing in food or water which will be later ingested.

Hyperthermia experiments were performed by applying an oscillating magnetic field of chosen amplitude 100 Oe with frequency of $873 \mathrm{kHz}$ to several identical solutions of bacteria and MNPs. To study cell viability as a function of temperature, magnetic heatings were performed at the same heating up rate up to different maximum temperatures. Bacterial survival was assessed through colony forming units (CFU) count, while confocal laser scanning (CLS) microscopy was used to evaluate cellular membrane integrity. It is important to remark that all the experiments have been performed in triplicate, in at least three independent assays, for a meaningful statistical evaluation of the results.

\section{EXPERIMENTAL PROCEDURE}

PAA-Coated $\mathrm{Fe}_{3} \mathrm{O}_{4}$ Nanoparticles: Magnetite nanoparticles of $\sim 10 \mathrm{~nm}$ have been synthesized in aqueous solution by chemical coprecipitation of a stoichiometric mixture of $\mathrm{Fe}^{3+}$ $\left(\mathrm{FeCl}_{3 .} 6 \mathrm{H}_{2} \mathrm{O}, 97 \%\right)$ and $\mathrm{Fe}^{2+}\left(\mathrm{FeSO}_{4 .} 7 \mathrm{H}_{2} \mathrm{O}, 99 \%\right)$ ions in 


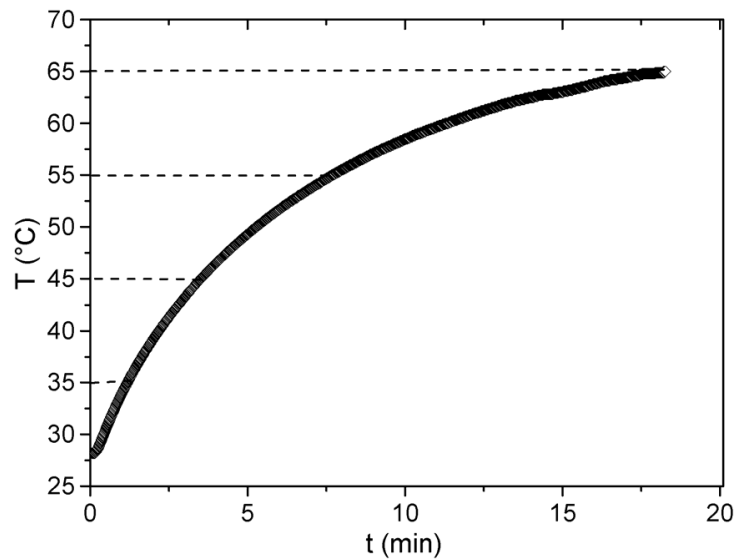

Fig. 1. Time dependence of temperature induced by hyperthermia effect of aqueous solutions containing magnetite nanoparticles and Pseudomonas fluorescens. Dash lines show the maximum temperatures used in this work at which sample solutions have been heated by this technique.

the molar ratio $\mathrm{Fe}^{3+} / \mathrm{Fe}^{2+}=1.49$ with ammonium hydroxide $\left(\mathrm{NH}_{4} \mathrm{OH}, 28 \%\right)$. Poly-acrylic acid-coated magnetite nanoparticles, $\mathrm{Fe}_{3} \mathrm{O}_{4} @$ @PA, were obtained by addition of poly-acrylic acid (PAA) immediately to the solution after precipitation of magnetite, in a molar ratio 50:1 regarding the total amount of total Fe. Magnetite structural phase was confirmed by X-ray powder diffraction and particle size and distribution was measured by transmission electron microscopy (TEM) (data not shown). Magnetic properties were measured as a function of an applied magnetic field in a vibrant sample measurement (VSM) magnetometer at room temperature and up to 2 Tesla.

Bacterial Strains and Culture Conditions: For each assay, P. fluorescens ATCC 27663 (ATCC-American Type Collection Culture) was subcultured on tryptic soy agar (TSA; Merck) for $24-48 \mathrm{~h}$ at room temperature $\left(20 \pm 2^{\circ} \mathrm{C}\right)$ and then grown in $30 \mathrm{ml}$ of tryptic soy broth (TSB, Merck) for $18 \pm 2 \mathrm{~h}$ at room temperature with agitation at $120 \mathrm{r} / \mathrm{min}$. Cells were then harvested by centrifugation at $7000 \mathrm{rcf}$ at $4{ }^{\circ} \mathrm{C}$ for $5 \mathrm{~min}$, and washed twice with $0.9 \%$ sterile saline. Finally, the cellular suspension was adjusted to a final concentration of $\approx 1 \times 10^{8}$ cells per $\mathrm{mL}$, determined by optical density at $640 \mathrm{~nm}$.

Hyperthermia Experiments: Magnetic hyperthermia experiments were performed by applying an oscillating magnetic field of amplitude $100 \mathrm{Oe}$ with frequency of $873 \mathrm{kHz}$ to several identical solutions containing bacteria and MNPs. An optical fiber was immersed in $1 \mathrm{~mL}$ of solution placed in the midpoint of a water cooled refrigerated coil to register the generated temperature increase versus time under application of the oscillating magnetic field. A high vacuum was achieved in the chamber around the sample to avoid heat transfers from the electronics to the sample and so false temperature readings. To study cell viability as a function of temperature, magnetic heatings were performed at the same heating up rate by exposing the samples to the external magnetic field for different times. The solution composition $\left(\mathrm{Fe}_{3} \mathrm{O}_{4} @\right.$ PAA nanoparticle and bacteria concentrations) was selected taking into account the time scale needed to achieve the desired maximum temperatures. Optimal results were obtained using a magnetite nanoparticle based ferrofluid of $16 \mathrm{~g} / \mathrm{L}$ and bacteria cells solutions of $10^{8} \mathrm{CFU} / \mathrm{mL}$ in a volume ratio=1 and using $1 \mathrm{~mL}$ of total volume. Fig. 1 shows the continuous temperature increase observed for one of these sample

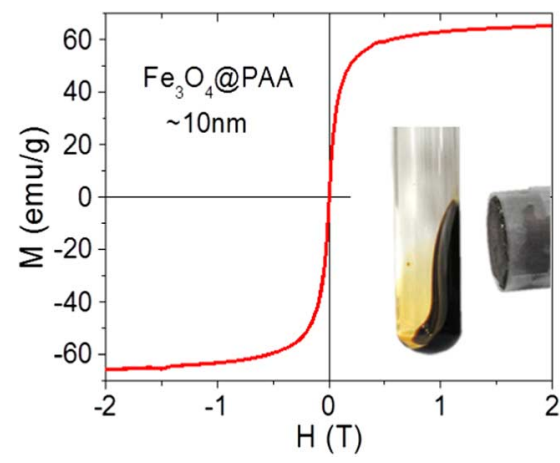

Fig. 2. Magnetization curve as a function of the applied magnetic field for $\mathrm{Fe}_{3} \mathrm{O}_{4} @$ PAA nanoparticles at room temperature. Inset shows a real picture about how this ferrofluid behaves in aqueous solution under an applied magnetic field produced by a permanent magnet.

solutions as a function of the time of exposure to the external alternating magnetic field. By stopping the experiment at different times we can heat sample solutions at different maximum temperatures, i.e., $55^{\circ} \mathrm{C}$ (maximum temperature used in the hyperthermia experiments in this work) are achieved in about $8 \mathrm{~min}$.

Survival Cells Enumeration: Survival of the bacterial cells was determined by CFU enumeration. In order to do so, the content of each sample tube was serially diluted in $0.9 \%$ saline and plated in TSA. Plates were incubated for at least $24 \mathrm{~h}$ at $37^{\circ} \mathrm{C}$ prior to $\mathrm{CFU}$ count.

Cellular Membrane Integrity Assessment: After the hyperthermia treatments, samples were stained with a commercial kit that allows differentiating living and dead bacterial cells (LIVE/ DEAD BacLight Bacterial Viability Kit, Molecular Probes, Invitrogen). This kit is composed by two fluorophores, SYTO 9 (green dye, for living cells) and Propidium Iodide (red dye, for dead cells). First of all, samples were stained with $3 \mu \mathrm{L}$ of a mixture of these two fluorophores (1:1) for 10 minutes in darkness. Then, in order to get a representative amount of cells in the images, samples were concentrated by centrifugation at $5000 \mathrm{r} / \mathrm{min}$ for $5 \mathrm{~min}$ at $4{ }^{\circ} \mathrm{C}$. After careful removing of the supernatants, the cellular pellets were resuspended in $50 \mu \mathrm{L}$ of ultrapure water. Finally, $5 \mu \mathrm{L}$ of the final solution was dispensed in a glass slide and covered with a glass coverslip that was sealed with nail polish.

Confocal imaging was carried out with a $40 \mathrm{X}$ oil immersion objective of a Carl Zeiss inverted microscope attached to the LSM 780 confocal system (software; ZEN 2010) (Carl Zeiss Microimaging GmbH, Göttingen, Germany). Fluorescence images shown as sequential photographs were acquired at 512 $\times 512$ pixel resolution in the same region but separately for each fluorophore and then mixed to prevent interfaces. Argon laser $488 \mathrm{~nm}$ was used to get the imaging from SYTO 9 in the green channel and diode-pumped solid-state (DPSS) $561 \mathrm{~nm}$ laser was used to get the imaging from Propidium Iodide in the red channel.

\section{RESULTS AND DISCUSSION}

Fig. 2 shows the magnetization of $\mathrm{Fe}_{3} \mathrm{O}_{4} @$ PAA nanoparticles of average particle size around $10 \mathrm{~nm}$ as a function of the 


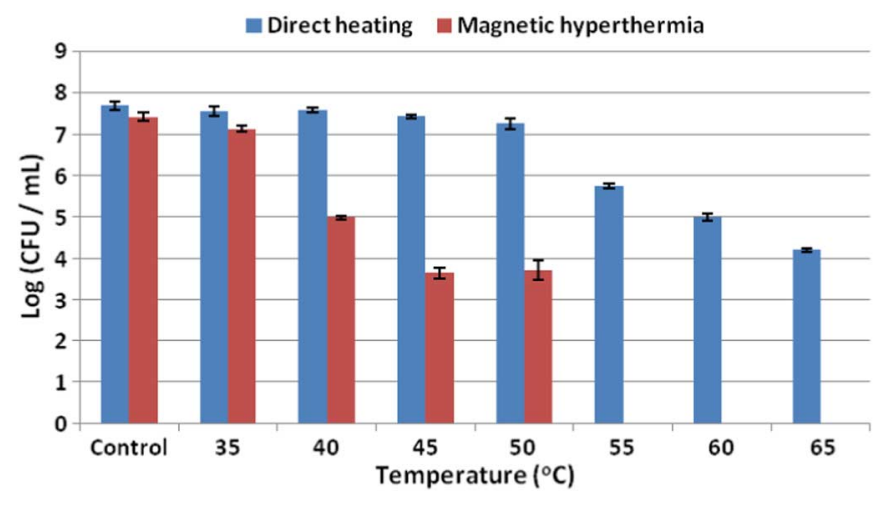

Fig. 3. Colony forming units counted in solutions after hyperthermia experiments as a function of the maximum temperatures achieved by hyperthermia (red) and direct heating (blue).

applied magnetic field at room temperature. They show superparamagnetic behavior with relatively high saturation magnetization, which is closer to the bulk magnetization $(80-90 \mathrm{emu} / \mathrm{g})$ when subtracting the nonmagnetic PAA shell mass that is not contributing to the total magnetism. This PAA coating around the nanoparticles prevents the magnetic properties from the core and provides them with higher stability in aqueous solution, behaving as a ferrofluid under an applied magnetic field (see image in Fig. 1).

Identical solutions containing MNPs and P. fluorescens cells were remotely heated by hyperthermia effect using an electromagnetic field of amplitude 100 Oe with $873 \mathrm{kHz}$ frequency. Experiments were performed for different times, achieving different maximum temperatures. To compare its performance against a conventional direct heating, bacteria solutions of the same concentration were heated in a Thermomixer (Eppendorf Ibérica) by increasing temperature up to the same specific values as in hyperthermia. In those, temperature was measured directly inside the solution by immersing a thermocouple. Fig. 3 shows the colony forming units count after both heating procedures as a function of maximum temperature reached in the experiments. Results correspond to a statistical analysis of at least three independent assays, each one performed in triplicate, which were subjected to the identical heat treatment.

The efficient heating properties of $\mathrm{Fe}_{3} \mathrm{O}_{4}$ @PAA nanoparticles under an oscillating magnetic field allow inducing irreversible damage to the bacteria cells, provoking their death in a short time. Although cell viability results showed a nonremarkable reduction in the bacteria population when temperature increased up to $35{ }^{\circ} \mathrm{C}$, a significant reduction $(3 \mathrm{Log})$ of viable planktonic cells was observed when a higher maximum temperature of $40^{\circ} \mathrm{C}$ was reached, corresponding to only about 3 minutes of exposure to alternate magnetic field. A complete cellular eradication was achieved after only $\sim 8$ minutes, when the temperature was increased up to $55^{\circ} \mathrm{C}$. The concrete reason why no differences were found between the number of survival cells at $45^{\circ} \mathrm{C}$ and $50^{\circ} \mathrm{C}$ in hyperthermia needs further investigation, but it might be related to the presence of a small population of heat resistant cells, which indicates that population is heterogeneous with regard to heat resistance [12], [13]. The better performance of the technique was demonstrated by comparing its

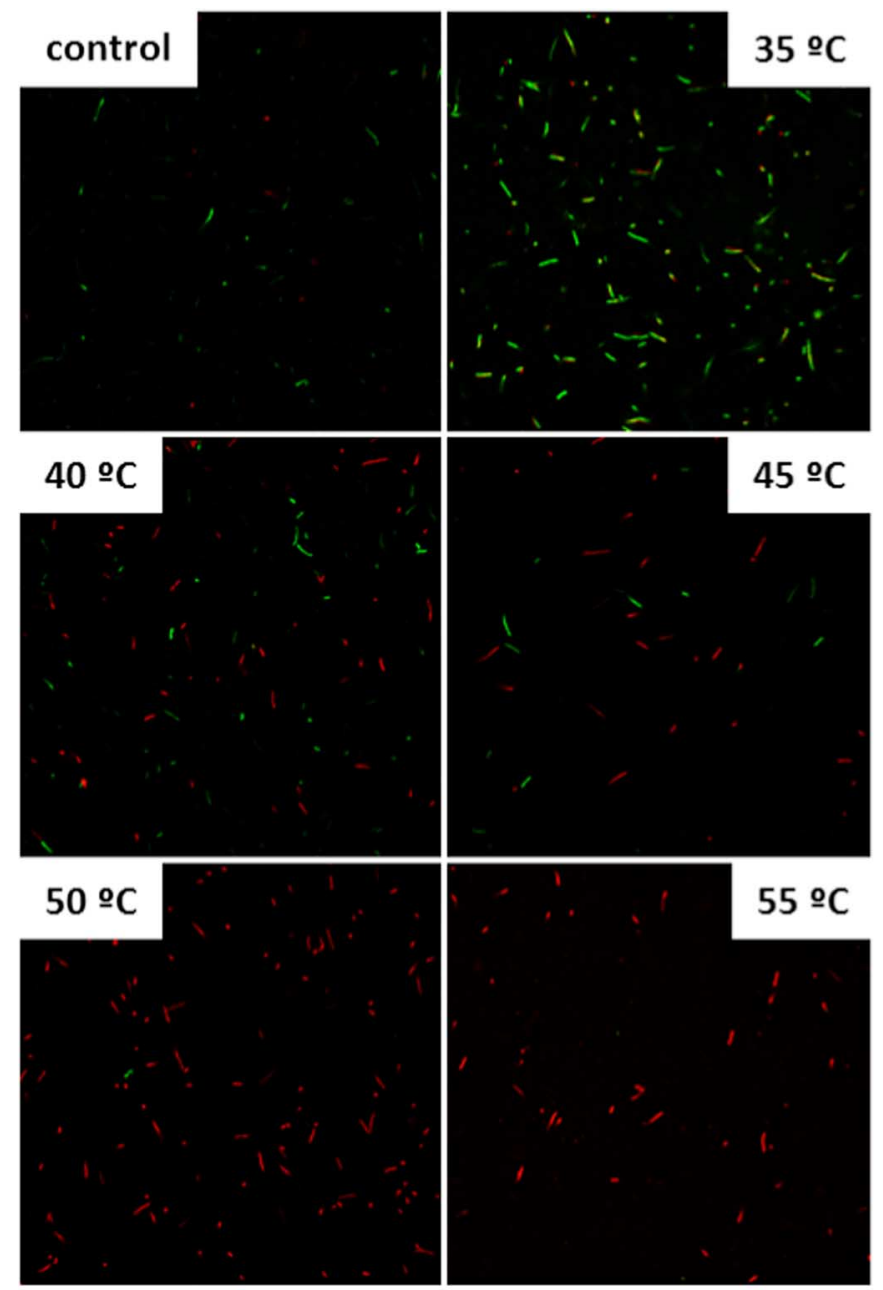

Fig. 4. CLS fluorescence images of identical magnetite nanoparticles and bacteria aqueous solutions labeled with the live/dead fluorescence kit for bacteria after reaching different maximum temperatures by hyperthermia effect.

results with those obtained from a conventional direct heating method. Above $35^{\circ} \mathrm{C}$, a significant higher increase in the cell death is observed by hyperthermia. Even when the average solution temperature is the same by both heating methods, the local heating induced by hyperthermia in the nanoparticles originates a local higher temperature increase that provokes more irreversible damages in the neighboring bacteria cells around. In fact, at the temperature of total cellular eradication in hyperthermia, direct heating only decreased a bit the number of viable bacteria, showing no complete eradication even at $65^{\circ} \mathrm{C}$. CLS microscopy was performed after magnetic hyperthermia to correlate results with those from colony forming units count. To clearly distinguish which cells are alive or dead, $3 \mu \mathrm{L}$ of a mixture of green- and red-fluorescent nucleic acid stains (SYTO 9 and propidium iodide, respectively) were added to the samples, keeping them in darkness to allow the fluorochromes acting for $10 \mathrm{~min}$. Both green- and red-dyes differ in their spectral fluorescence properties and also their mechanism of labeling is based on their ability to specifically penetrate healthy bacterial cells and attach to the inner nucleic acid. Whereas SYTO 9 dye generally labels all the bacteria in a population with either intact or damaged membranes, in contrast, propidium iodide pen- 
etrates only bacteria with damaged membranes, causing a reduction in the SYTO 9 stain fluorescence when both dyes are present. Taking this into account bacteria showing red fluorescence are considered as nonviable cells and bacteria showing green fluorescence are considered as viable cells. Fig. 3 shows CLS images of samples stained with the LIVE/DEAD kit after hyperthermia at different maximum temperatures. Those confirm that the damages inflicted by magnetic hyperthermia in the P. fluorescens cells affect irreversibly their cellular membrane integrity and decrease their viability, so they can be considered as dead bacteria. The amount of red stained cells increased substantially with magnetically induced thermal treatment. At 40 ${ }^{\circ} \mathrm{C}$, a considerable number of red cells was observed, in good agreement with the significant population reduction observed in the CFU count at that temperature. When temperature was increased up to $55^{\circ} \mathrm{C}$, no green-labeled cells were observed, meaning that complete eradication of bacteria population takes place in the temperature range between $50^{\circ} \mathrm{C}$ and $55^{\circ} \mathrm{C}$, again in total agreement with the cell survival count.

\section{CONCLUSIONS}

High-quality structural and magnetic PAA-coated magnetite nanoparticles of an average particle size around $10 \mathrm{~nm}$ have been synthetized to be used as heating sources under an oscillating magnetic field. Their heating properties have allowed heating efficiently solutions containing both magnetic nanoparticles and a food spoilage microorganism, $P$. fluorescens. In comparison to a direct heating method, magnetic hyperthermia showed a better performance; bacteria cell populations were more efficiently reduced at lower final solution temperatures. Cell survival assays, both CFU counts and CLS images of properly fluorescent labeled bacteria, confirm a complete eradication of bacteria cell population by achieving $55^{\circ} \mathrm{C}$ in less than $\sim 8$ min through magnetic hyperthermia. Although further studies should be addressed in real bacterial biofilm systems, these preliminary results open the possibility of using MNPs-based hyperthermia out of the biomedical field as a potential method of disinfection in food and water related biological systems, preserving at the same time the biological functionalities of the nutrients present in them when compared with traditional disinfection methods.

\section{ACKNOWLEDGMENT}

This work was supported in part by the European Community's under the FP7-Cooperation Programme through the MAGISTER project "Magnetic Scaffolds for in vivo Tissue Engineering" Large Collaborative Project FP7 and from European Regional Development Fund (ERDF) under the Northern Regional Operational Programme ON.2-O Novo Norte- for the acquisition of the main equipment used in this research. D. R. also acknowledges the financial support of Portuguese Foundation for Science and Technology (FCT) through the grant SFRH/BPD/72632/2010.

\section{REFERENCES}

[1] S. H. Ko, I. Park, H. Pan, C. P. Grigoropoulos, A. P. Pisano, C. K. Luscombe, and J. M. J. Fréchet, Nano Lett., vol. 7, no. 7, pp. 1869-1877, 2007.

[2] B. D. Terris and T. Thomson, J. Phys. D: Appl. Phys., vol. 38, no. 12, pp. R199-R222, 2005.

[3] Y. Li and G. A. Somorjai, Nano Lett., vol. 10, no. 7, pp. 2289-2734, 2010.

[4] A. G. Roca, R. Costo, A. F. Rebolledo, S. Veintemillas-Verdaguer, P. Tartaj, T. Gonzalez-Carreño, M. P. Morales, and C. J. Serna, J. Phys. D: Appl. Phys., vol. 42, no. 22, pp. 224002-2240012, 2009.

[5] M. Bañobre-López, Y. Piñeiro-Redondo, R. De Santis, A. Gloria, L. Ambrosio, A. Tampieri, V. Dediu, and J. Rivas, J. Appl. Phys., vol. 109, no. 7, pp. 07B313-07B315, 2011.

[6] J.-H. Lee, J.-T. Jang, J.-S. Choi, S. H. Moon, S.-H. Noh, J.-W. Kim, J.-G. Kim, I.-S. Kim, K. I. Park, and J. Cheon, Nature Nanotechnol., vol. 6, no. 7, pp. 418-422, 2011.

[7] Y. Piñeiro-Redondo, M. Bañobre-López, I. Pardiñas-Blanco, G. Goya, M. A. López-Quintela, and J. Rivas, Nanoscale Res. Lett., vol. 6, pp. 383-389, May 2011.

[8] R. B. Campbell, Nanomedicine, vol. 2, no. 5, pp. 649-652, 2007.

[9] J. W. Costerton, Z. Lewandowske, D. E. Caldwell, D. R. Korbre, and H. M. Lappin-Scott, Ann. Rev. Microbiol., vol. 49, pp. 711-745, Oct. 1995.

[10] B. Song and L. Leff, Microbiol. Res., vol. 160, no. 2, pp. 111-117, 2005.

[11] P. Baker and L. Leff, Biofilms, vol. 2, no. 1, pp. 1-7, 2005.

[12] T. H. Wood, Advan. Biol. Med. Phys., vol. 4, pp. 119-165, Feb. 1956.

[13] W. A. Moats, J. Bacteriol., vol. 105, no. 1, pp. 165-171, 1971 